\title{
Erratum: "Effect of a Gas Discharge on the Ignition in the Hydrogen-Oxygen System" [Kinetics and Catalysis 46, 776 (2005)]
}

\author{
R. S. Konstantinovskii, V. M. Shibkov, and L. V. Shibkova \\ Faculty of Physics, Moscow State University, Vorob'evy gory, Moscow, 119899 Russia \\ Submitted June 11, 2004; accepted for publication June 11, 2004
}

DOI: $10.1134 / \mathrm{S} 0023158406010216$

On page 776, right column, line 14 from bottom: The inequality $E / n \geq 10^{15} \mathrm{~V} \mathrm{~cm}{ }^{2}$ should be read $E / n \geq 10^{-15} \mathrm{~V} \mathrm{~cm}^{2}$. 